\title{
FORMAÇÃO HUMANA E O ENSINO RELIGIOSO NA EDUCAÇÃO INFANTIL
}

\author{
HUMAN EDUCATION AND RELIGIOUS EDUCATION IN EARLY CHILDHOOD \\ EDUCATION
}

\author{
Jacqueline Crepaldi Souza \\ Doutora e Mestra em Ciências da Religião \\ pela Pontifícia Universidade Católica de Minas Gerais - PUC Minas. \\ Belo Horizonte, Minas Gerais, Brasil. \\ jacquelinecrepaldisouza@gmail.com
}

\begin{abstract}
Resumo: No Brasil, a Educação Infantil, primeira etapa da educação básica, tem como finalidade o desenvolvimento integral da criança em seus aspectos físico, psicológico, intelectual e social. Atrelada a essas dimensões está a religiosidade, abertura da pessoa ao sentido da vida, espaço de humanização da criança. Neste contexto, o artigo tenta responder à seguinte pergunta: "O Ensino Religioso é capaz de ajudar na formação humana das crianças da Educação Infantil?" Objetiva-se analisar a relação entre a formação humana e a dimensão religiosa da criança da Educação Infantil. A metodologia qualitativa e bibliográfica contou com autores como La Taille (2009), Winnicott (1975; 1983; 1999), Gruen (1994), Lévinas (1993) e Agostinho de Hipona (1984). Como conclusão, afirma-se que abordar a religiosidade como abertura à construção de sentido requer educação e cuidado, numa sociedade que, por vezes, se torna sem sentido, reproduzindo grande vazio existencial nas crianças.
\end{abstract}

Palavras-chave: educação infantil; ensino religioso; formação humana; sentido.

Abstract: Early Childhood Education in Brazil, the first stage of basic education, aims at the integral development of the child in its physical, psychological, intellectual and social aspects. Religiosity is indeed linked to these dimensions as openness of the person to the meaning of life and the space of humanization of the child are. In this context, the article tries to answer the following question: "Is Religious Education capable of assisting in the human education of children in early childhood education?" The purpose of this article is to analyze the relationship between human education and the religious dimension of children in early childhood education. The qualitative and bibliographical methodology included authors such as La Taille (2009), Winnicott (1975, 1983, 1999), Gruen (1994), Lévinas (1993) and Augustine of Hipona (1984). As a conclusion, it is said that approaching religiosity as an opening to the construction of meaning requires education and care in a society that sometimes becomes meaningless, reproducing a great existential emptiness in children.

Keywords: child education; religious education; human formation; meaning.

\section{Para citar - (ABNT NBR 6023:2018)}

SOUZA, Jacqueline Crepaldi. Formação humana e o ensino religioso na educação infantil. Eccos - Revista Científica, São Paulo, n. 58, p. 1-18, e13509, jul./set. 2021. Disponível em: https://doi.org/10.5585/eccos.n58.13509. 


\section{Introdução}

$\mathrm{Na}$ Educação Infantil os eixos curriculares são as interações e as brincadeiras. ${ }^{1}$ Tendo em vista estes eixos, torna-se essencial interligá-los à dimensão religiosa da criança para sua formação humana. Uma formação que considera as crianças nos seus contextos sociais, ambientais, culturais e nas interações e práticas sociais (BRASIL, 1998, p. 23). Essas funções também fornecem elementos para linguagens, contatos com conhecimentos variados e construção de uma identidade autônoma. Educar é apresentar a vida, e não dizer como viver (SAYÃO, 2016).

Interligando-se o Referencial Curricular para a Educação Infantil ao tema aqui tratado, destaca-se que cuidar é "estar comprometido com o outro, com sua singularidade" (BRASIL, 1998, p. 25). Cuidar da dimensão religiosa da criança e educá-la exigem ética. Estão em jogo valorizar, anular ou direcionar as descobertas religiosas da criança. Sem proselitismos, cabe a cada educador ter em mente que, com a ética da alteridade ${ }^{2}$, é possível construir uma educação de qualidade que contemple integralmente o desenvolvimento da criança. Isso inclui sua religiosidade. $^{3}$

As crianças da educação contemporânea nasceram no início do terceiro milênio. $O$ entendimento do que é "ser criança" ganhou não apenas importância, mas novos significados com a criação de arcabouços jurídicos nacionais e internacionais em relação ao tema. A Lei de Diretrizes e Bases 9394/1996 (BRASIL, 1996) declara que a educação escolar brasileira se compõe de dois níveis: Educação Superior e Educação Básica; esta, formada por Educação Infantil, Ensino Fundamental e Ensino Médio. O conceito e a finalidade da Educação Infantil (BRASIL, 2013) encontram-se no artigo 29 dessas diretrizes: “Art. 29. A Educação Infantil, primeira etapa da Educação Básica, tem como finalidade o desenvolvimento integral da criança de até 5 (cinco) anos, em seus aspectos físico, psicológico, intelectual e social, complementando a ação da família e da comunidade."

Cuidar da dimensão religiosa da criança e educá-la fazem parte da educação sistemática que, antes de ensinar ou supor respostas, estimule a criança à busca de sentidos, ao questionamento, a verbalizar suas perguntas e a respeitar as interrogações dos outros. Nessa perspectiva, reconhecer a dimensão religiosa no desenvolvimento infantil pode contribuir para

\footnotetext{
${ }^{1}$ Cf. BRASIL, 2010, p. 25-27.

${ }^{2}$ Alteridade como resposta que se dá às diferenças, sem dominação.

3 O termo "religiosidade" indica algo que "antecede" o fenômeno religioso e a adesão de fé a uma tradição religiosa. Tanto o fenômeno religioso quanto a

confissão religiosa são expressões de algo mais amplo e anterior chamado religiosidade. Portanto, Gruen (1994, p. 75) afirma que a religiosidade "está à raiz da vida humana na sua totalidade". A religiosidade caracteriza-se pela atitude dinâmica de abertura da pessoa ao sentido fundamental de sua existência, seja qual for o modo como percebe este sentido. Ou seja, na raiz da vida humana há uma abertura para o sentido da vida, isto é a religiosidade.
} 
o processo educativo e formador integral da criança. Educar a religiosidade é parte da construção histórico-cultural da pessoa. ${ }^{4}$

Numa visão antropológica, entende-se como religiosidade uma das dimensões humanas, isto é, a pessoa possui dimensões física, psíquica e de religiosidade que se interpenetram e se influenciam mutuamente. ${ }^{5}$ Pela dimensão física, a pessoa se situa no espaço e no tempo dentro do universo. A corporeidade é o lugar em que todas as dimensões se manifestam. A dimensão psíquica compreende o centro emotivo, a inteligência e a memória. A dimensão de religiosidade, também chamada de "eu profundo", é a dimensão de onde provém o sentido da existência, tanto da vida quanto da morte. Para Brugnara (1995, p. 31), as pessoas que esquecem essa dimensão ou vivem sem dar-lhe atenção sentem inexplicável sensação de vazio interior e tentam preenchê-lo, a qualquer custo, com excessos, vícios ou outros paliativos. Em decorrência disto, com o passar do tempo, esses aparatos acabam por revelar o sentido que ainda não encontraram, razão pela qual é importante, desde cedo, valorizar a dimensão religiosa da criança.

Em Agostinho de Hipona (1984), educar é cuidar. Ele dizia que se morre de falta de pão, mas se morre também pelo excesso de pão. Transferindo esta máxima para a educação, vê-se que o excesso de atividades para crianças retira-lhes a leveza de viver esta fase tão importante da vida que é a infância. É preciso cuidar da dimensão pessoal e social desta criança. Neste viés, a educação como formação humana e socialização das crianças dialoga com aquilo que Lévinas designa como alteridade: responsabilizar-se pelo outro, sem dominação.

Neste modelo de educação, a pessoa torna-se referência. O ideal educativo da formação humana para a alteridade se compara ao proposto por Charlot (1983, p. 88), ao dizer que o que há de essencial na pessoa não muda. O que pode modificar são os meios postos em ação para se aproximar desse ideal; meios que dependem das circunstâncias de tempo, de lugar, de sujeito. Eis a significação social de educação que não muda com o tempo: educar para a alteridade!

\section{Conceitos basilares para o trabalho com o Ensino Religioso}

No Ensino Religioso, a formação humana situa as crianças como seres sociais na contemporaneidade. ${ }^{6}$ Essa formação acontece com interações e brincadeiras na Educação Infantil. Marcas de cuidado ou descuido com o outro, com o mundo e com a natureza são

\footnotetext{
${ }^{4}$ Diversos autores citam as dimensões psíquica, social, somática e religiosa como dimensões humanas (FRANKL, 1989; VYGOTSKY, 1991; WALLON. 2007). ${ }_{5}^{5}$ Baptista (2016, p. 119) diz que o objeto do Ensino Religioso é expresso na categoria antropológica "religiosidade" e supera uma concepção limitada de transposição didática das Ciências da Religião para esse ensino.

${ }^{6}$ Entende-se "sociedade contemporânea" como lugar de transformações econômicas, políticas, sociais e culturais. A sociedade atual é denominada por muitos estudiosos de sociedade do conhecimento, sociedade técnico-informacional ou sociedade tecnológica, o que significa dizer que o conhecimento, o saber e a ciência assumem um papel muito mais destacado do que anteriormente (LIBÂNEO; OLIVEIRA; TOSCHI, 2012. p. 61-66).
} 
trazidas para a escola e, nas interações, revelam o mundo das crianças, suas dúvidas e preocupações. Enfim, há um espaço e tempo favoráveis para trabalhar sua formação humana. E a religiosidade fará parte dessa construção.

A consequência do trabalho com a dimensão religiosa, quando psicopedagógica e epistemologicamente qualificado, é a educação para o sentido de vida. ${ }^{7}$ Sua pretensão não é ensinar uma religião, mas educar a religiosidade enquanto abertura à solidariedade, aos valores, à plenitude de vida (GRUEN, 1994, p. 9). Os principais conceitos aqui desenvolvidos estão em consonância com Wolfgang Gruen (1994), cujo estudo sistemático a respeito do Ensino Religioso Escolar provocou grande impacto na educação. Entre eles, podem-se citar: 1) Conceito de Ensino Religioso: insubstituível fator educativo para os alunos, sejam quais forem suas opções em termos de religião. Não visa ensinar uma religião, mas educar a "religiosidade"; 2) Conceito de religiosidade: atitude dinâmica de abertura da pessoa ao sentido de sua existência. Não se trata de "mais uma" atitude ou função: a religiosidade é uma dimensão profunda da vida humana (GRUEN, 1994, p. 24); 3) Conceito de religião: uma maneira concreta de a pessoa viver a sua religiosidade, que, normalmente, se dará em comunidade e, portanto, com todas as contingências históricas, mudanças e expressões culturais que isso implica, daí as diversas religiões (GRUEN, 1994, p. 25); 4) Objetivo central do Ensino Religioso, segundo Gruen: ajudar o aluno a formular existencialmente o questionamento religioso e a dar resposta de compromisso para suas atitudes.

Nesta perspectiva, o conceito de alteridade será essencial. Perceber a presença ou ausência da alteridade no discurso de educandos e educadores ajuda a identificar fundamentos, teorias e práticas para o trabalho com o Ensino Religioso. Ao tornar-se alguém integralmente responsável pelo outro, a singularidade da pessoa é respeitada, porque ninguém pode ser responsável em nosso lugar. O outro provoca este movimento ético em minha consciência. Lévinas (1993, p. 54) diz que: "quanto mais assumo minhas responsabilidades, mais me torno responsável". O pronome "ele" exprime irreversibilidade, ou seja, "eleidade" 8 , de onde se origina a alteridade do ser. Com Lévinas (1993), pode-se afirmar que no encontro com o outro é que o ser tem um sentido.

Além disso, é necessário que se faça distinção fundamental entre o Ensino Religioso plural e o confessional. O modelo plural de Ensino Religioso respeita a alteridade e toma como ponto de partida não apenas os diversos sistemas de enfoques e respostas, mas a própria atitude

\footnotetext{
${ }^{7}$ Destaca-se a religiosidade das crianças da Educação Infantil como abertura ao sentido da vida.

${ }^{8}$ Eleidade como diferença absoluta do outro; ele é ele, ela é ela, e não se comparam a nada que se mostra. No face a face com o outro, estamos face a face com o transcendente.
} 
de busca e questionamento na diversidade humana. O Ensino Religioso é laico e se faz na diversidade de linguagem, de cosmovisões e de motivações. Diferentemente do Ensino Religioso confessional, que compete à família ou à comunidade de fé, este modelo não alimenta a identidade religiosa da pessoa. Alimenta, sim, a alteridade da pessoa, fortificando sua maneira de ver o outro, escutá-lo e responsabilizar-se por ele. Enfim, forma-se como ser humano, ser de sentido.

A brincadeira também significa construção de sentido pela criança. Sendo autora de sua história e com um olhar sensível e crítico, a criança fala com o brincar não só de seu mundo e de sua ótica de criança, mas do mundo adulto, da sociedade contemporânea. Vygotsky (1991) aproxima-se desta concepção ao postular que no brincar está a fonte para se tornar uma pessoa determinada. Leloup (1998) recorda que quando escutamos nossa corporeidade podemos encontrar a felicidade em nós mesmos.

Muitas vezes é no brincar que a criança vive suas primeiras perdas. No compartilhamento de bens, por exemplo, especialmente nas famílias com um ou dois filhos, os problemas são propensos a ocorrer quando a criança pequena recebe uma visita. Nessas ocasiões, é esperado que ela compartilhe seus bens com os colegas. Embora as crianças possam resistir, aprendem logo que tal compartilhamento é temporário. A propriedade real dos objetos nunca é desafiada. Na Educação Infantil as coisas são diferentes, porque todos os brinquedos e materiais educativos são propriedade comum; dependem de combinados para sua posse temporária. Segundo Corsaro (2011, p. 132), é no decurso desses combinados que as crianças tentam estabelecer propriedade conjunta dos objetos. Se há alteridade, há respeito pelo outro, porque o vemos como pessoa com quem podemos compartilhar. Quando não há alteridade no modo como nos relacionamos com o outro, o vemos como coisa, e não aceitamos dividir nossos bens, nem nosso afeto. As imagens construídas nos relacionamentos desde a infância são diretrizes para o comportamento futuro.

\section{A criança na cultura}

Em relação à família e à cultura, nota-se que a criança da Educação Infantil nasceu numa época em que os pais, sempre ocupados com o trabalho, os estudos e a tecnologia, muitas vezes não têm tempo para os filhos. Para suprir esta falta, a satisfação imediata de todas as vontades das crianças, com elogios como "você é ótima, admirável, excelente", ajuda a criar uma autoestima artificial. A criança pode passar a negar seus fracassos e a legitimar os juízos alheios com consequente mergulho numa vida fantasiosa. Quando se apagam os limites a serem 
transpostos, passando à criança a ideia de que ela pode tudo, ou quando se reforçam esses limites com humilhação, criam-se altas muralhas intransponíveis. Segundo La Taille (1999, p. 41):

Seja pelo excesso de mimo, seja pela humilhação, falhamos em estimular a criança a procurar a superação, a tentar alcançar o lado de lá de seus atuais limites, a dar valor à excelência; paralisamos o movimento que leva de uma situação inferior para uma situação superior [...].

Os valores se expressam nas famílias com os "pais satisfatórios" que nutrem a confiabilidade das crianças. A expressão "mãe satisfatória" foi criada por Winnicott (1999, p. 139) para explicar a adaptação da mãe às necessidades do bebê. Ao confiar que suas necessidades serão satisfeitas, o bebê passa a dar continuidade a seu desenvolvimento, início de sua saúde mental. ${ }^{9}$ A plenitude e riqueza de todas as dimensões da vida da criança dependem desse sutil início do desenvolvimento humano. Segundo Winnicott (1975, p. 154), confiar significa interagir previsivelmente com o outro. A mãe funciona como um "espelho" para seu filho, no qual a qualidade afetiva que se estabelece é capaz de refletir de volta para a criança aspectos do seu comportamento expressivo.

A função de espelho desempenhada pela mãe contribui para o estabelecimento da confiança. Com o reforço da relação entre a função de espelho no início da vida infantil e a confiança, Winnicott afirma que, "quando uma família permanece íntegra e tem de si algo em desenvolvimento, durante certo tempo, cada criança extrai benefícios daí: pode se ver na atitude de cada um dos membros ou na atitude da família como um todo". A metáfora do espelho ajuda a compreender a oportunidade que a criança tem de ver os pais e demais pessoas, olhando a si mesma. Assim, ela vai construindo sua personalidade. A esse respeito, Papalia e Feldman (2013, p. 213) relatam pesquisas recentes que identificaram células especiais do cérebro chamadas "neurônios espelhos", que podem ser a base do altruísmo:

\footnotetext{
Os neurônios espelhos, localizados em várias partes do cérebro, são ativados quando a pessoa faz alguma coisa, mas também quando ela observa outro indivíduo fazendo o mesmo. Ao "espelharem" as atividades e motivações dos outros, permitem que se veja o mundo do ponto de vista da outra pessoa.
}

Se, por um lado, os neurônios espelhos permitem que se veja o mundo do ponto de vista da outra pessoa, por outro, quanto maior a falta de confiança na outra pessoa, maiores as possibilidades de decepção, e como consequência o estabelecimento da perda de sentido pela

\footnotetext{
${ }^{9}$ Winnicott explica que, para o bebê, confiar é receber de volta o que está dando. O rosto da mãe não é um espelho, mas é no rosto que "a percepção toma o lugar da apercepção. Toma o lugar do que poderia ter sido o começo de uma troca significativa com o mundo, um processo de duas direções no qual o autoenriquecimento se alterna com a descoberta do significado no mundo das coisas vistas" (WINNICOTT, 1975, p. 154).
} 
criança. Transferindo o cuidado corporal para o cuidado emocional, a confiança nos pais se revela nos acontecimentos diários. ${ }^{10}$ Para Winnicott (1983, p. 63),

o desenvolvimento emocional ocorre na criança quando se proveem condições suficientemente boas, vindo o impulso para o desenvolvimento de dentro da própria criança. As forças no sentido da vida, da integração da personalidade e da independência são tremendamente fortes, e com condições suficientemente boas a criança progride; quando as condições não são suficientemente boas essas forças ficam contidas dentro da criança e de uma forma ou de outra tendem a destruí-la.

As forças de sentido da vida, integração da personalidade e independência têm seu impulso dentro da própria criança. É indispensável que agências como a família e a escola estejam unidas no desafio de educar as crianças (GRUEN, 1994, p. 93), cuidando de todas as suas dimensões e, em especial, das emoções e de sua dimensão religiosa. La Taille (1999, p. 71) explica que, “cada vez que damos liberdade, damos responsabilidade. O valor pedagógico da primeira deve ser avaliado em função da importância da segunda, pois dar liberdade sem dar responsabilidade é, na verdade, não dar a liberdade”. Pais e educadores da atualidade podem motivar as crianças a buscarem a sua felicidade, sem se esquecerem da responsabilidade com o outro.

Esse equilíbrio entre o estímulo e a busca de excelência também é tarefa primordial da educação. A educação é formadora de cultura. Entretanto, a sociedade atual, por vezes, tem mostrado um modelo educacional insustentável. Levando à violência e a disputas, esse modelo falido revela discriminação, preconceitos e ganância. Talvez ele esteja se formando dentro das próprias escolas. Quando não se ensina a esperar sua vez, quando não há diálogo, quando não se educam as crianças para lidar com as diferenças, perde-se a oportunidade de ensinar a alteridade e a possibilidade de contribuir para gerar cidadania. Para completar o quadro atual, não se escutam as dúvidas e medos das crianças (L'ECUYER, 2015). A imagem das crianças como plantas a serem regadas se quebrou (ARROYO, 2009); outras metáforas se fazem necessárias para a educação contemporânea. É preciso pensar uma nova educação para um novo ser humano. O sentido existencial torna-se eixo dessa educação. Ele pretende formar uma pessoa que vê sentido na vida.

Entende-se que um tratamento didático para lidar com a dimensão religiosa está vinculado a uma complexidade de assuntos que, devido à sua pluralidade, necessitam de aprofundamento. O ponto de partida deve ser o conhecimento do educando. Autores como Piaget (1975, 1977, 1999), Fowler (1992), Amatuzzi (2001) e Frankl (1989) ajudam a descobrir

\footnotetext{
${ }^{10}$ Segundo Ricarte et al. (2013, p. 157), a palavra "emoção", etimologicamente, provém do latim emotionem, movimento, comoção, ato de mover. Essa palavra deriva-se de uma forma composta de duas palavras - ex: fora, para fora, e motio: movimento, ação, comoção, gesto. Em seus estudos, Ricarte et al. (2013, p. 160) explicam que "da relação emocional com o outro nascerão as funções simbólicas da atividade intelectual e as condutas sociais adaptadas".
} 
como se dá a formação dessa criança e em que consiste o sentido existencial ou o vazio existencial de uma pessoa. Cooperação, fé, superação do medo e propósito de vida são destacados pelos autores como suportes para a busca do sentido pela criança.

Jung (1964, p. 165) afirma que "a infância é um período de grande intensidade emocional". Às vezes, um acontecimento real, impressionante e inesquecível marca a criança com recordações que nenhum adulto notou. Ao chegar à escola, fase de estruturação do ego e da adaptação ao mundo exterior, acontecem choques e embates dolorosos. As imperfeições do mundo e o mal que existe dentro e fora de nós tornam-se problemas conscientes. Nesta fase, as crianças buscam algum sentido na vida para lidar com o caos existente dentro e fora delas (FRANS, 1964, p. 166). Entretanto, um novo dilema surge: a tensão entre a imagem e o conceito. A consciência moderna bane a imaginação de sua função antropológica de enraizamento existencial do ser humano. Barreto (2008, p. 20) descreve que "esse processo vem desaguar na hegemonia de uma razão instrumental que recusa a coincidência ontológica entre o verdadeiro, o bom e o belo, e chama a si a tarefa de moldar o mundo humano em todas as suas dimensões".

Entretanto, o mundo das crianças, banido de imaginação, faz com que elas se sintam entediadas, gerando desinteresse, cansaço do futuro, vazio da inércia, preconceitos, cinismo, exaustão, falta de coletividade e de cooperação. Enfim, por se sentir tolhida em suas vontades ou desejos, a criança projeta suas frustrações sobre qualquer objeto exterior: acusa Deus, seus pais, a situação financeira, o lugar onde mora como responsáveis por sua frustração. As "sombras sobre o futuro" (JUNG, 1964, p. 167) aparecem como em contos de fadas e nas histórias do rei e da rainha que não podiam ter filhos.

O talismã que cura a tristeza do rei ou da rainha torna-se algo peculiar, como a trança de uma moça bondosa e, mais tarde, a própria moça. O remédio para afastar o mal é sempre difícil de ser encontrado. Se a "tristeza do rei e da rainha são símbolos de nossos vazios e futilidades", o remédio, quer dizer, o talismã, não pode ser qualquer coisa. Neste aspecto, o trabalho com a dimensão religiosa é como este talismã que afasta o mal que existe dentro e fora das crianças. É uma ferramenta que pode ser usada para fortalecer a criança contra esses males. Nas conversas com as crianças, ensinar alteridade torna-se um talismã precioso num mundo repleto de preconceitos e violência. Mas onde há expressão desse talismã, ou seja, da religiosidade da criança? 


\section{A criança e sua religiosidade}

Nas próprias expressões das crianças encontram-se os dilemas e suas respostas. Por exemplo, durante uma aula de Ensino Religioso, uma menina de 4 anos tornou-se ansiosa e agressiva na sala. Ao conversar com ela, a professora ouviu que seus pais haviam brigado no dia anterior. Ela, parada no meio da sala, assistia à briga, e, quando o pai gritou que fosse para o quarto, ela não se mexeu: "Eu congelei como uma estátua!"

Esse exemplo não traduz apenas uma emoção. Ele vai ao encontro do que Tillich (1964) chama de "toque religioso", uma experiência profunda provocada por um acontecimento. Esse "toque religioso" envolve a pessoa e a "prende", fazendo-a "sair da mera objetividade das coisas e penetrar no seu nível mais profundo, em que a raiz do ser das coisas toca o homem, fala com ele e o prende" (RUEDELL, 2007, p. 47). Fatos negativos, como o da "menina-estátua", ou fatos positivos, como o nascimento de um irmão, um dente que cai, uma semente que brota, podem tocar as crianças, alegrando-as ou entristecendo-as, tirando-as do indiferentismo. Esses toques religiosos não são privilégio de alguns; todas as crianças podem vivenciá-los no dia a dia, sem apresentar aparência religiosa. Podem estar também desconectados de instituições sagradas. Assim, em Tillich (1970), afirma-se que deixar a criança viver esse momento sagrado é ajudá-la a se deparar com sua dimensão religiosa, no chão de sua cultura. $\mathrm{O}$ encontro com o transcendente se dá exatamente aí. ${ }^{11}$

Portanto, cuidar da dimensão religiosa da criança e educá-la é refletir, criticamente, a respeito da realidade na qual se vive, tarefa árdua, quando se trata de crianças de 4 e 5 anos, mas necessária. A criança lê o mundo e reconhece nele as fragilidades humanas. Ela vê o pobre, o faminto, o sem-teto. E traz esses temas para a escola. O Ensino Religioso não pode ser espaço para apenas se “conhecer religiões diferentes”. Ensino Religioso é espaço para a criança agradecer pelo seu alimento, mas também refletir a respeito da criança que não tem o que comer, que precisa de pão, roupa, saúde e educação. É espaço de reflexão sobre o respeito e a dignidade humana. Talvez, ainda na Educação Infantil, propiciar uma interação entre crianças de escolas diferentes, creches, escolas carentes seja o início do sentido existencial para a criança.

A criança não procura por Deus, mas busca significado para sua própria existência e para os acontecimentos do mundo. Por isso ela tem tantos “porquês”. Ela busca sentido. Quando não há sentido, há deserto. A espiritualidade ou o toque religioso impele a criança a buscar. Mas é a religiosidade que a faz deixar-se conduzir. Figueiredo (1994, p. 46) relata que a

\footnotetext{
${ }^{11}$ Antropologicamente, Tillich não nomeia os seres divinos, mas refere-se a eles pelas expressões "Incondicionado", "Absoluto". Neste texto, utiliza-se a terminologia "transcendente", apontando para além de nossa humanidade. Conforme Ruedell (2007, p. 48), "em linguagem teológica, que é usada no discurso de fé religiosa, as divindades recebem nomes de acordo com a respectiva confissão: Deus, Javé, Alá, Shiva, Vishnu, Tupã, etc."
} 
dimensão religiosa é a predisposição do ser para a experiência religiosa individual que nasce do eu mais profundo. A abertura a esta dimensão de religiosidade é caracterizada por Frankl (2011, p. 29), por dois fenômenos humanos: o amor e a consciência. O amor faz a pessoa transcender-se em direção a outro ser humano. A consciência o transcende em busca de sentido.

A educação do início do Terceiro Milênio nos convida a analisar o atual conceito de educação que atenderá à criança contemporânea. Deste conceito nasce o modo como a escola aborda a dimensão religiosa da criança. Brandenburg (2013, p. 156-157) atesta que a forma como a dimensão religiosa é concebida no projeto Político-Pedagógico da escola revela sua abordagem. Ruedell (2007, p. 147), por exemplo, defende o enfoque antropológico-cultural. Para ele, as expressões culturais estão impregnadas de religiosidade.

O currículo é a relação com o mundo. Um espiral de continuidade e de emergência do novo. É um complexo tecido em conjunto. Partindo dos estudos de Morin, Moraes (2010, p. 295) diz que:

A complexidade pode ser compreendida como um princípio regulador do pensamento
e da ação, aquilo que não perde de vista a realidade dos fenômenos, que não separa a
subjetividade da objetividade e não exclui o espirito humano, o sujeito, a cultura e a
sociedade. É o olhar complexo sobre os fenômenos que nos permite, segundo esse
autor, encontrar um substrato comum à biologia, à física è antropologia. É esse olhar
que nos possibilita encontrar uma certa abertura epistemológica capaz de estender a
noção de sistema um pouco mais além da física e da biologia, na tentativa de
compreender não apenas a natureza ordenada/desordenada da matéria e o
funcionamento dos sistemas vivos, mas também as organizações sociais como
unidades complexas.

Esta complexidade indica as dimensões humanas interligadas. Somos simultaneamente seres físicos, biológicos, sociais, culturais, psíquicos e espirituais. Assim, "nada acontece ao nosso espírito que não afete a nossa matéria corporal” (MORAES, 2010, p. 296). Espírito e matéria estão em união. Portanto, a complexidade torna-se um fator constitutivo da vida que responde pelo entrelaçamento existente entre os fenômenos e os processos constitutivos da dinâmica natural da própria vida. A transdisciplinaridade aponta novos entendimentos para o mundo e seus problemas para produção e difusão do conhecimento requerido pelo século XXI (ANTÔNIO DE PAULA, 2008, p. 19).

O currículo da complexidade reconhece a alteridade como característica basilar da contemporaneidade. Seu enfoque é a transdisciplinaridade. O conteúdo vale, mas valem mais as relações sociais, afetivas e emocionais que refletem condições socio- históricas e culturais importantes vividas pelos sujeitos aprendentes (MORAES, 2010, p. 300). No interior da escola uma diversidade de olhares, de sentido, de sensibilidade e significado, de culturas, de pluralidades de mestiçagem favorece referências, pluralidade de linguagens e interpretações da 
realidade. O pensamento complexo exige aceitação da diferença. A primeira razão da exigência da transdisciplinaridade é o caráter e a amplitude dos desafios que o novo século nos apresenta. Antônio de Paula (2008, p. 19) cita como alguns exemplos a violência das metrópoles, a crise ambiental e os robôs.

A infância revela atitudes que "são reflexos de um contexto moral ou imoral maior" (ARROYO, 2009, p. 46). As crianças reproduzem na escola os valores que são obrigadas a viver. Complicados processos de sua socialização formam esses valores. Um tempo apressado forma crianças apressadas. Um tempo de cinismo forma crianças cínicas. Um tempo de violência forma crianças violentas. Entretanto, há o mundo da sensibilidade que pode formar crianças sensíveis e responsáveis pelo outro. Verdadeiros líderes, sem preconceitos, dignos em todas as suas dimensões humanas.

Assim, a realidade do educando tem prioridade sobre o currículo. Duas dimensões do ser humano merecem atenção: a pessoal e a social. Seco $(2009$, p. 51) vê que esta relação compõe-se de liberdade e responsabilidade. Antropologicamente, os componentes humanos essenciais, como felicidade, amor, liberdade, busca da verdade, vontade, Deus, estão em luta permanente porque "a vida humana é combate e na capacidade escondida de muitas de nossas decisões se encontra a raiz do egoísmo" (SECO, 2009, p. 73). Agostinho de Hipona é consciente desses dois amores: o amor de Deus, fonte de felicidade, e o amor próprio, fonte de posse e dominação. $^{12}$

Neste sentido, um dos maiores objetivos do Ensino Religioso na Educação Infantil é o diálogo permanente entre a construção de sentido da vida e a alteridade. Falar em alteridade é fazer um diagnóstico de nosso tempo. Perguntas e problemas inquietantes exigem atitudes de flexibilidade e mudança. Seco (2009, p. 85) afirma que o centro medular de uma proposta educativa de sucesso conflui em dupla aprendizagem: aprender a ser e aprender a compartilhar. Síntese da Pedagogia agostiniana, este conceito engloba habilidades, como o autocontrole, a tenacidade, o entusiasmo, a motivação, a arte de escutar e a alteridade. Nesse modelo, os valores têm papel primordial.

Aliás, a educação em valores é outro objetivo do Ensino Religioso na Educação infantil. Segundo Seco (2009, p. 89), aprender a ser se educa na interioridade, na verdade e na liberdade responsável. Aprender a compartilhar se educa no respeito, na justiça e na solidariedade. Os critérios pedagógicos para uma educação em valores são: 1) Conhecer-se, aceitar-se, superarse: isto significa sabedoria; conhecer-se é descobrir uma dimensão mais profunda do ser,

${ }^{12}$ A história de Agostinho revela esses dois opostos: aridez da insensibilidade e fecundidade da sensibilidade (AGOSTINHO, 1984, p. 51-57). 
percebendo-a como interioridade; esta dimensão mais profunda não significa ensimesmar-se. Pelo contrário, neste espaço íntimo, nesta casa de valores (SECO, 2009, p. 105), a maior alegria é saber-se protagonista de uma história singular. Há pessoas que se desconhecem de si mesmas. Como disse Agostinho (1984, p. 276), “os homens vão admirar os cumes das montanhas, as ondas do mar, as largas correntes dos rios, o oceano, o movimento dos astros, e deixam de lado a si mesmos". Conhecer-se é saber que na vida há prazeres, desencantos e crises; 2) Educar para o compromisso: isto porque as pessoas são "vontades", como diz Agostinho de Hipona. Educar para o compromisso é ajudar a despertar nas pessoas a alteridade; 3) Educar para a amizade fortalece as crianças da solidão e da fragilidade. Tudo isso indica que a educação necessita de uma mística, uma espiritualidade, um sentido profundo, um toque religioso. Esses estimuladores de valores são motivadores educacionais. Sem eles a educação se reduz a normas, prêmios e deveres artificiais, um corpo sem alma. Essa mística é a sensibilidade pelo valor e vocação de um ser humano (DEL RIO, 2006, p. 40).

Portanto, os princípios de uma Pedagogia que abranja esses aspectos podem se ancorar na Pedagogia humanística proposta por Agostinho de Hipona. O educador humano (FINCIAS, 2006, p. 41) parte das necessidades do educando. A pessoa se torna inquieta buscando respostas para suas perguntas. “A inquietude é o que a mantém em permanente peregrinação" (DEL RIO, 2006, p. 51). Para Agostinho de Hipona, esta inquietude leva a pessoa para Deus. Numa cosmovisão sapiencial, Del Rio (2006, p. 52) afirma que toda prática educativa não deve circunscrever-se e terminar no âmbito de meros conhecimentos naturais ou imanentes (ciência), mas devem, sim, conectar e terminar em conhecimentos transcendentes (sabedoria).

Em outras palavras, o objeto da razão é a realidade sensível (ciência). O objeto sapiencial é o conhecimento das realidades inteligíveis (sabedoria). Deste modo, a metodologia adequada a esta visão é a de que o conhecimento geme com dores de parto; resta-nos descobrilo. Assim, a maiêutica, ou seja, "arte do parto", foi um conhecido método socrático para buscar a verdade. "Como a mãe ao dar à luz o filho necessita da ajuda da parteira, assim o educando necessita do estímulo e ajuda do educador para vislumbrar a verdade que leva dentro de si" (DEL RIO, 2006, p. 56). Com Agostinho de Hipona percebe-se o educar (e-ducere = tirar) como ajudar a dar a luz à verdade que as pessoas e as coisas levam dentro de si. Del Rio (2006, p. 56) aponta que 
a tarefa de educador deve centrar-se em fazer acender no aluno essas imagens divinas que as pessoas e as coisas levam impressas em si mesmas e que são sua verdade, seu logos. Aqui, o trabalho do educador, antes de instruir ou informar, é convidar, estimular, provocar, despertar, guiar e ajudar o aluno no conhecimento das verdades que não são outras coisas que os "inteligíveis seminais". Porque é ao aluno que corresponde colocar o maior esforço e realizar a função essencial de trazer a luz da verdade. Definitivamente se trata de um sistema de aprendizagem em que o protagonismo é exercido pelo discípulo em que a autoformação prevalece sobre a heteroformação.

Neste sistema, no qual a autoformação prevalece sobre a heteroformação, o professor convida à formação humana, científica e cultural. Ele ajuda o aluno a reconhecer suas potencialidades humanas. Assim, o caráter dialógico precisa estar presente desde as aulas na Educação Infantil, período no qual tem que provocar, estimular e ajudar o aluno a olhar para dentro de si. O sentido da vida já está nele. Ele precisa agora abrir as portas e janelas de seu interior para descobrir qual sentido é este. A formação pedagógica do professor e da professora tem função primordial nesta empreitada. Mas qual Ensino Religioso dará conta desta proposta de ensinar religiosidade e alteridade para as crianças da Educação Infantil?

\section{Matriz para o ensino religioso na educação infantil}

A resposta talvez esteja na Matriz para o Ensino Religioso na Educação Infantil, cujas bases se ancoram nas dimensões de religiosidade e alteridade. Nasce a Pedagogia do educar e cuidar da dimensão religiosa da criança como revela o Quadro 1. 
Quadro 1 - Matriz do Ensino Religioso para a Educação Infantil

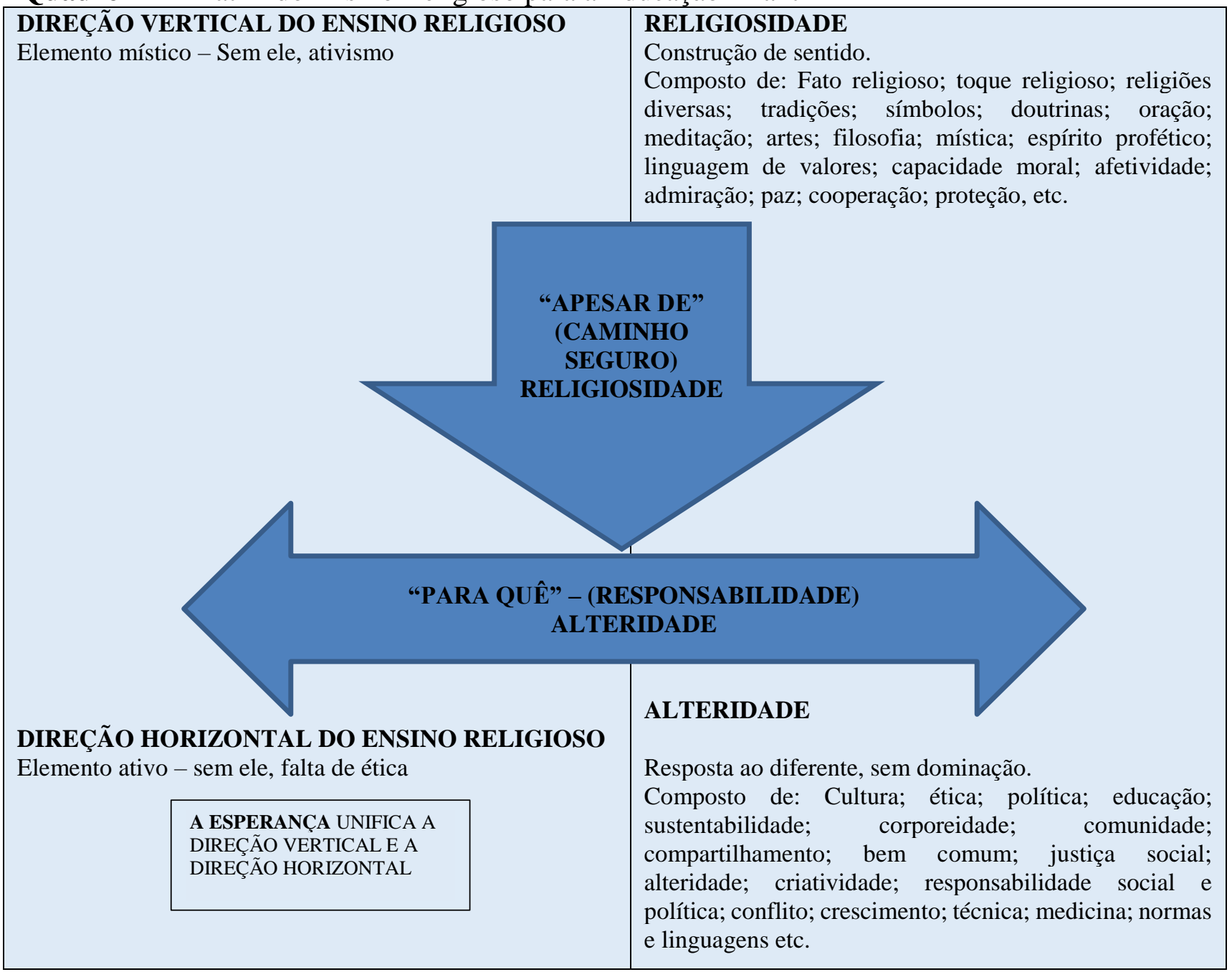

Fonte: Elaborado pela autora.

Conforme o Quadro 1, as direções vertical e horizontal do Ensino Religioso orientam este ensino. A direção vertical do Ensino Religioso é a religiosidade sempre presente ao ser como construção de sentido e significa a resposta que a pessoa dá aos desafios da vida. A religiosidade experimenta sua capacidade de "apesar de" tudo encontrar forças para seguir em frente com dignidade. A linguagem de valores, a capacidade moral, o toque religioso, a religião, o fato religioso, a comunidade, o espírito profético são expressões dessa religiosidade. Sem ela, um ativismo toma conta do Ensino Religioso. ${ }^{13}$

A direção horizontal do Ensino Religioso é a dimensão da alteridade e significa a atitude que a pessoa tem ao expressar a força de sua religiosidade. A luta pela justiça social, a valorização de culturas diversas, a política, a educação, a sustentabilidade, a corporeidade são exemplos da dimensão de alteridade. Se esta dimensão for negligenciada faltará a ética.

\footnotetext{
${ }^{13}$ Ativismo indica a atitude (às vezes racionalizada em teoria filosófica) que assume como princípio a subordinação de todos os valores, inclusive a verdade, às exigências da ação, isto é, ao êxito ou ao sucesso da ação (quase sempre a ação política) (ABBAGNANO, 2007, p. 90).
} 
Pensando ser dona de tudo, a pessoa se achará dona das outras pessoas. O preconceito se fortalecerá e ferirá a justiça social. No entanto, se for

\section{Conclusão}

Como conclusão, afirma-se que uma fundamentação pedagógica que defina competências, currículo e metodologia do Ensino Religioso na Educação Infantil torna-se base necessária para a desafiadora, porém encantadora, tarefa de cuidar da dimensão religiosa da criança e educá-la. Seu maior desafio é o fato de que a criança de 4 e 5 anos está tentando ser competente em diversas habilidades. No desenvolvimento da iniciativa, por exemplo, envolta na descoberta do ciclo vital, a esperança ou a falta dela definem o olhar dessa criança para a vida: abrir-se ao outro, confiando, ou fechar-se, desconfiando de tudo. Confiar é encontrar sentido.

A matriz do Ensino Religioso para a Educação Infantil deve se fundamentar em dois eixos: o sentido da vida (religiosidade) e a justiça social (alteridade). Com ela responde-se o problema de nosso artigo, afirmando-se que o Ensino Religioso é capaz de ajudar na formação humana das crianças da Educação Infantil, pois essa formação se dá ao educar a criança e cuidar de sua dimensão religiosa.

\section{Referências}

ABBAGNANO, Nicola. Dicionário de filosofia. São Paulo: Martins Fontes.

AGOSTINHO, Santo. 1984. Confissões. São Paulo: Paulus, 2007.

AMATUZZI, Mauro Martins. Esboço de teoria de desenvolvimento religioso. In: PAIVA, Geraldo José de. et al. Entre necessidade e desejo: diálogos da Psicologia com a religião. São Paulo: Loyola, 2001.

ARROYO, Miguel G. Imagens quebradas: trajetórias e tempos de alunos e mestres. Petrópolis: Rio de Janeiro, 2009.

BAPTISTA, Paulo Agostinho Nogueira. O problema do objeto do Ensino Religioso. Anais do VII Simpósio Internacional de Ciências da Religião da PUC Minas: O PPGCR e os desafios da pós-graduação, 12 set. 2016.

BARRETO, Marco Heleno. Imaginação simbólica. São Paulo: Loyola, 2008. 
BRANDENBURG, Laude Erandi. A espiritualidade na escola e a tradição religiosa familiar. In: KRONBAUER, Selenir Corrêa Gonçalves; SOARES, Afonso Maria Ligorio. Educação e religião: múltiplos olhares sobre o Ensino Religioso. São Paulo: Paulinas, 2013.

BRASIL. Base Nacional Comum Curricular para a Educação Infantil. Disponível em: http://basenacionalcomum.mec.gov.br/abase/\#infantil. Acesso em 28 set. 2018. (2018b).

BRASIL. Lei de Diretrizes e Bases da Educação Nacional. Disponível em: http://portal.mec.gov.br/docman/julho-2013-pdf/13677-diretrizes-educacao-basica-2013pdf/file. Acesso em: 28 set. 2018.

BRASIL. Lei 9.394/96, 20 de dezembro de 1996. Lei do Ensino Religioso. Disponível em: http://www.planalto.gov.br/ccivil_03/LEIS/19394.htm. Acesso em: 12 maio 2018

BRASIL. Ministério da Educação e do Desporto. Secretaria de Educação Fundamental. Departamento de política da educação fundamental. Coordenação-geral de Educação Infantil. Subsídios para credenciamento e funcionamento de instituições de Educação Infantil. Brasília, maio de 1998. Disponível em: http://portal.mec.gov.br/seb/arquivos/pdf/scfiei.pdf Aceso em 10 jan. 2019.

BRASIL. Ministério da Educação. Secretaria de Educação Básica. Diretrizes curriculares nacionais para a educação infantil / Secretaria de Educação Básica. Brasília: MEC, SEB, 2010. Disponível em http://portal.mec.gov.br/index.php?option=com_docman\&view=download\&alias=9769diretrizescurriculares-2012\&category_slug=janeiro-2012-pdf\&Itemid=30192. Acesso em 05 jan. 2019.

BRUGNARA, Roque. Pessoa humana e religião. São Paulo: FTD, 1995.

CAMBI, Franco. História da pedagogia. São Paulo: Unesp, 1999.

CHARLOT, Bernard. A mistificação pedagógica: realidades sociais e processos idelógicos na teoria da educação. 2. ed. Rio de Janeiro: Zahar, 1983.

CORSARO, William A. Sociologia da infância. Porto Alegre: Artmed, 2011.

DEL RIO, Isaías Díez. Pressupostos filosóficos e antropológicos de la pedagogia agostiniana. In: BERDON, Eusebio B. OSA. (Org.). Elementos básicos de pedagogia agostiniana. Roma: Publicazione Agostiniane Curia Generalizia Agostiniana, 2006.

FIGUEIREDO, Anísia de Paulo. Ensino religioso: perspectivas pedagógicas. Petrópolis, Rio de Janeiro: Vozes, 1994.

FINCIAS, Francisco Galende. O modelo educativo agostiniano. In: BERDON, Eusebio B. OSA. (Org.). Elementos básicos de pedagogia agostiniana. Roma: Publicazione Agostiniane Curia Generalizia Agostiniana, 2006.

FOWLER, James W. Estágios da fé. Rio Grande do Sul: Sinodal, 1992.

FRANKL, Viktor Emil. Sede de sentido. São Paulo: Quadrante, 1989. 
FRANZ, Marie Louise Von. O processo de individuação. In: JUNG, Carl Gustav. (Org.). $O$ homem e seus símbolos. Rio de Janeiro: Nova Fronteira, 1964.

GRUEN, Wolfgang. O ensino religioso na escola. Petrópolis, Rio de Janeiro: Vozes, 1994.

JUNG, Carl G. O homem e seus símbolos. Rio de Janeiro: Nova Fronteira, 1964.

LA TAILLE, Yves de. Limites: três dimensões educacionais. 2. ed. São Paulo: Ática, 1999.

LA TAILLE, Yves de; MENIN, M. S. E. (Org.). Crise de valores ou valores em crise? Porto Alegre: Artmed, 2009.

L'ECUYER, Catherine. Educar na curiosidade: como educar num mundo frenético e hiperexigente? São Paulo: Edições Fons Sapientiae, 2015.

LELOUP, Jean-Yves. O corpo e seus símbolos: uma antropologia essencial. Rio de Janeiro: Vozes, 1998

LÉVINAS, Emanuel. Humanismo do outro homem. Rio de Janeiro: Vozes, 1993.

LIBÂNEO, José Carlos; OLIVEIRA, João Ferreira de; TOSCHI, Mirza Seabra. Educação Escolar: políticas, estrutura e organização. São Paulo: Cortez, 2012.

MORAES, Maria Cândida. Complexidade e currículo: por uma nova relação. Polis Revista de la Universidad Bolivariana, v. 9, n. 25, 2010.

PAPALIA, Diane E.; OLDS, Sally Wendkos; FELDMAN, Ruth Duskin. Desenvolvimento humano. São Paulo: Mcgraw-Hill, 2009.

PAULA, João Antônio de. A transdisciplinaridade e os desafios contemporâneos. Belo Horizonte: Editora UFMG, 2008.

PIAGET, Jean. A formação do símbolo na criança. Rio de Janeiro: Zahar, 1975.

PIAGET, Jean. A linguagem e o pensamento da criança. São Paulo: Martins Fontes, 1999.

PIAGET, Jean. O julgamento moral da criança. São Paulo: Mestre Jou, 1977.

RICARTE, Mirela Dantas; MINERVINO, Carla Alexandra da Silva Moita; DIAS, Maria da Graça Bompastor Borges; ROAZZI, Antônio. Emoções infantis: estudos do reconhecimento das emoções em diferentes contextos sociais. In: Aprendizagem e emoção: estudos na infância e adolescência. MINERVINO, Carla Alexandra da Silva Moita; NÓBREGA, Juliana das Neves (Orgs.). São Paulo: Casa do psicólogo, 2013.

RUEDELL, Pedro. Educação religiosa. Fundamentação antropológica cultural da religião segundo Paul Tillich. São Paulo: Paulinas, 2007.

SAYÃO, Rosely. Educação sem blá-blá-blá: como preparar seus filhos e alunos para o convívio familiar, a escola e a vida. São Paulo: Três estrelas, 2016. 
SECO, Santiago M. Insunza. OSA. Uma pedagogia com dios al fondo: El carácter próprio de um Centro Educativo Agustiniano. Madri: Federação Agustiniana Española (FAE), 2009.

TILLICH, Paul. La dimension perdida: indigência e esperanza de nuestro tempo. Nueva biblioteca de Teologia. Editorial Española Desclée de Brouwer, Bilbao, 1970.

VYGOTSKY, Lev Semenovitch. A formação social da mente. São Paulo: Martins Fontes, 1991.

WALLON, Henri. A evolução psicológica da criança. São Paulo: Martins Fontes, 2007.

WINNICOTT, Donald Woods. O ambiente e os processos de maturação: estudos sobre a teoria do desenvolvimento emocional. Porto Alegre: Artmed, 1983.

WINNICOTT, Donald Woods. O brincar e a realidade. Rio de janeiro: Imago, 1975.

WINNICOTT, Donald Woods. Tudo começa em casa. São Paulo: Martins Fontes, 1999. 